\title{
Concentration of Trichloroethylene in Breast Milk and Household Water from Nogales, Arizona
}

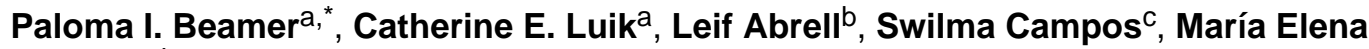 \\ Martínez $^{\mathrm{d}}$, and $\mathbf{A}$. Eduardo Sáez ${ }^{\mathrm{e}}$ \\ aMel and Enid Zuckerman College of Public Health, University of Arizona, 1295 N. Martin Ave, \\ Tucson, AZ, 85724, USA \\ ${ }^{\mathrm{b}}$ Arizona Laboratory for Emerging Contaminants, University of Arizona, 1040 E. $4^{\text {th }} \mathrm{St}, \mathrm{Rm} .611$ \\ Tucson, AZ, 85721, USA \\ 'Mariposa Community Health Center, 1852 Mastick Way, Nogales, AZ, 85621, USA \\ dMoores UCSD Cancer Center, University of California, San Diego, 3855 Health Sciences Drive, \\ \#0901, La Jolla, CA, 92093, USA \\ ${ }^{e}$ Chemical and Environmental Engineering, University of Arizona 1133 E. James E. Rogers Way, \\ Tucson, AZ, 85721, USA
}

\begin{abstract}
The United States Environmental Protection Agency has identified quantification of trichloroethylene (TCE), an industrial solvent, in breast milk as a high priority need for risk assessment. Water and milk samples were collected from 20 households by a lactation consultant in Nogales, Arizona. Separate water samples (including tap, bottled and vending machine) were collected for all household uses: drinking, bathing, cooking, and laundry. A risk factor questionnaire was administered. Liquid-liquid extraction with diethyl ether was followed by GCMS for TCE quantification in water. Breast milk underwent homogenization, lipid hydrolysis and centrifugation prior to extraction. The limit of detection was $1.5 \mathrm{ng} / \mathrm{mL}$. TCE was detected in 7 of 20 mothers' breast milk samples. The maximum concentration was $6 \mathrm{ng} / \mathrm{mL}$. TCE concentration in breast milk was significantly correlated with the concentration in water used for bathing $(\rho=0.59, p=0.008)$. Detection of TCE in breast milk was more likely if the infant had a body mass index $<14(\mathrm{RR}=5.2, \mathrm{p}=0.02)$. Based on average breast milk consumption, TCE intake for 5\% of the infants may exceed the proposed US EPA Reference Dose. Results of this exploratory study warrant more in depth studies to understand risk of TCE exposures from breast milk intake.
\end{abstract}

\section{Keywords}

exposure biomarkers; trichloroethylene; volatile organic compounds; solvents; children; minorities; drinking water quality

\section{INTRODUCTION}

Trichloroethylene (TCE), a halogenated hydrocarbon, is primarily used as a metal degreaser in electronics manufacturing, and in paint strippers, adhesive solvents, paints, and varnishes (1). TCE ranks $16^{\text {th }}$ on the Department of Health and Human Services 2011 Comprehensive

*Corresponding Author: 1295 N. Martin Avenue, P.O. Box 245210, Tucson, AZ, 85724, USA, Telephone: (520)-626-0006 Fax: (520) 626-8009, pbeamer@email.arizona.edu. 
Environmental Response, Compensation and Liability Act (CERCLA) Priority List (2) because of widespread contamination and significant potential threat to human health due to suspected toxicity and likelihood of exposure. TCE is present in at least $60 \%$ of hazardous waste sites proposed for inclusion on United States Environmental Protection Agency's (US EPA) Superfund National Priorities List (3), and is the most frequently reported organic contaminant in groundwater. It is also the $3^{\text {rd }}$ most frequently detected contaminant above its regulatory Maximum Contaminant Level (MCL) (4). Between 9-34\% of drinking water supplies in the US are estimated to have TCE contamination (1).

TCE exposure is associated with speech and hearing impairments, liver problems, skin rashes, diabetes, kidney disease, urinary tract, and blood disorders (5). TCE exposure may also have a role in autoimmune disease including systemic lupus erythematosus (SLE) (6) and is suspected to induce certain types of cancer, such as childhood leukemia, nonHodgkin's lymphoma, multiple myeloma, kidney, liver, and cervical cancers (7). A more recent review concluded that additional epidemiological studies further support association between TCE exposure and certain cancers (8).

Studies have demonstrated that early exposures may be more important even in development of adult cancer $(9,10)$, and there is a need for additional studies of prenatal and childhood exposures to carcinogens. Nursing infants have a unique exposure pathway via ingestion of contaminants in their mothers' breast milk. Due to its lipophilicity $\left(\log \mathrm{K}_{\mathrm{ow}}=2.29\right)$, TCE accumulates in breast milk. An infant nursing from a mother exposed to the occupational exposure limit for TCE could receive more than $80 \%$ of the daily lifetime advisory limit for adults (11). TCE was detected in all eight breast milk samples analyzed from four US cities; however, investigators did not quantify the TCE content (12). To the knowledge of the current study authors, the results of this study have not been replicated and no single study has quantified TCE content in breast milk despite its identification as a key priority by researchers and regulatory agencies $(1,3,13)$.

In 2007, Nogales, Arizona had drinking well closures due to TCE contamination (14). A TCE plume exists in Nogales as a result of solvent dumping at industrial site (15). As a city on the US-Mexico Border, there is potential for additional contamination from the rapid growth of industrial production in Mexico. Greater than 65\% of maquiladoras in Nogales, Sonora are involved in electronic manufacturing (16). Solvents, including TCE, constitute approximately $21 \%$ of the hazardous waste generated by these maquiladoras and there is concern that appropriate practices for environmental and worker safety may not be used (16, 17). The US-Mexico border dissects the watershed that supplies drinking water for Nogales, Arizona with predominate flow north from Mexico, and there is TCE contamination in drinking water in Nogales, Sonora (18). As late as 1992, one water official knew of no pretreatment of industrial wastes by maquilas before dumping in public drains (16). The incidence rates of some cancers associated with TCE exposure are higher in the Nogales region, compared to the state of Arizona $(19,20)$. The prevalence of SLE in Nogales, Arizona is two to seven times higher than the overall US prevalence $(21,22)$. Nogales was selected as the study site because of TCE contamination and increased frequency of certain diseases.

An exploratory study was conducted to quantify TCE in breast milk and household water samples from Nogales, Arizona. A risk factor questionnaire was used to determine if TCE content in breast milk is associated with exposure via water, other potential sources or sociodemographic variables. Considering the importance of breast-feeding as a protective factor for a number of diseases and health conditions, it is highly relevant to characterize infants' exposures and reduce exposure to nursing mothers (23). 


\section{METHODS}

\section{Field Sample and Data Collection}

Recruitment was completed through the Mariposa Community Health Center (MCHC), a federally qualified health center, in Nogales, Arizona. The breastfeeding program coordinator for the Women, Infants, and Children (WIC) program, operated through MCHC, identified potential participants and administered a screening questionnaire to determine eligibility. To be eligible, the mother needed to be 18 years of age or older, speak Spanish or English, and be participating in the WIC program or receiving breastfeeding consultations from MCHC. Eligible participants had to have an electric breast milk pump previously provided to them by WIC or MCHC. To assess depuration via breastfeeding, an effort was made to ensure that at least half of the participants were breastfeeding an infant under 3 months of age and/or breastfeeding their first child. Recruitment of 20 breastfeeding mothers was completed between February and April 2010. The study was approved by the University of Arizona Institutional Review Board. Written informed consent was provided in the language of choice (English or Spanish) and was also administered orally. A bilingual breastfeeding coordinator from MCHC, who was already working with these families, completed all field sample and data collection. An interviewer-administered questionnaire was completed in the participant's language of choice. Data were collected on the infant's physical characteristics, feeding and drinking habits, source of water for household uses, bathing and laundry routines, socio-demographic information, residential and employment history of the mother and other adults, as well as parity and breastfeeding history of the mother.

The mother collected the sample with her electric breast milk pump according to recommendations from Needham and Wang (24). The mothers were asked to wash the pump attachments in warm water prior to sample collection. Glass bottles $(5.75 \mathrm{oz})$ were provided for sample collection. Participants were asked to fill the bottle to the $4 \mathrm{oz}$ line or as close to it as possible in order to collect approximately $100 \mathrm{~mL}(3.38 \mathrm{oz})$ of milk. Bottle lids were lined with foil and bottles were covered with foil after sample collection to avoid exposure to UV light sources. Mothers were asked not to apply any lotions, soaps, or perfumes prior to sample collection and to wash their breasts with warm water before pumping. Two mothers were unable to provide $100 \mathrm{~mL}$ at one time and submitted a second sample 1 and 3 days later, respectively.

Water samples from all sources used for drinking, cooking, bathing and laundering by the adults as well as the infant in the household were collected according to questionnaire responses. Participants were asked if a different source was used specifically for the infants for each household use. Approximately $180 \mathrm{~mL}$ of water was collected in $250 \mathrm{~mL}$ amber glass bottles with lids lined with foil. The entire home visit lasted approximately one hour and participants were provided with a $\$ 45$ gift card to a local store.

Milk and water samples were transported from households to on ice, and stored at MCHC at $-20^{\circ} \mathrm{C}$ until transportation on ice to The University of Arizona. At the University, water samples were defrosted in a cold room $\left(4^{\circ} \mathrm{C}\right)$ and an aliquot was transferred from the original amber bottle to $40 \mathrm{~mL}$ amber glass vials with screw tops and septa to minimize headspace.

\section{Laboratory Analysis}

Samples were extracted and analyzed at the Arizona Laboratory for Emerging

Contaminants. TCE was extracted from water samples with diethyl ether in a 1:1 ratio (25). This method was selected because it is fast, requires a low sample volume, and reduces concern of TCE contamination in the extraction solvent while maintaining comparable 
precision and recovery to US EPA Method 551.1. Breast milk samples $(0.5 \mathrm{~mL})$ underwent homogenization, lipid hydrolysis through addition of $0.5 \mathrm{~mL} 50 \%$ aq. sodium hydroxide solution followed by $15 \mathrm{sec}$. vortexing and centrifugation at $4{ }^{\circ} \mathrm{C}$ and $5100 \mathrm{rpm}$ for $15 \mathrm{~min}$. Immediately afterward, $300 \mu \mathrm{L}$ of supernatant was transferred to $2 \mathrm{~mL}$ autosampler vials with $0.25 \mathrm{~mL}$ small volume inserts and analyzed by GC/MS. All empty and filled autosampler vials and centrifuge tubes masses were recorded.

All samples were analyzed with an Agilent 7890A gas chromatograph (GC) interfaced with a Waters Quattro micro tandem mass spectrometer (MS). The GC was equipped with an Agilent 7683 automatic liquid sampler and gas-tight syringe. A DB5-MS capillary column (30 m length $\times 250 \mu \mathrm{m}$ diameter $\times 0.25 \mu \mathrm{m}$ thickness) was used for all chromatographic separations. MS electron energy was $70 \mathrm{eV}$ in EI+ mode and selected ion monitoring was used to record mass of 131.89 (unfragmented TCE molecular weight). The source temperature was $250^{\circ} \mathrm{C}$ and the GC transfer line was held constant at $280^{\circ} \mathrm{C}$. Oven temperature started at $45^{\circ} \mathrm{C}$ and was held at this temperature for 4 minutes before ramping to $250^{\circ} \mathrm{C}$ at a rate of $60^{\circ} \mathrm{C} / \mathrm{min}$ then held at that temperature for the remainder of the run (total run time: 8 minutes). TCE eluted at 2.68 minutes. Helium was the carrier gas and held at a constant flow rate of $2 \mathrm{~mL} / \mathrm{min}$. The injector was operated using 5:1 split ratio and kept at $100^{\circ} \mathrm{C}$. Each sample injection volume was $2 \mu \mathrm{L}$ and three consecutive replicates of all standards and samples were analyzed. MassLynx 4.1 software (Waters Corporation, Milford, MA) was used to control GC-MS parameters and TargetLynx Application Manager software (Waters Corporation, Milford, MA) was used to integrate peak areas, determine limits of detection (LOD: described in Results), and create standard curves. Calibrants for water analysis were produced by adding TCE from a stock solution (1000 ppm in darkened $\mathrm{MeOH}$ mixed $24 \mathrm{hr}$ at $4^{\circ} \mathrm{C}$ ) to Type I clinical laboratory water by mass, followed by serial dilution with the same water. Calibrants for milk analysis were produced similarly on an analytical balance by adding TCE from a stock solution in $\mathrm{MeOH}$ to non-homogenized, warmed, mixed cow's milk followed by darkened mixing for $24 \mathrm{hr}$ at $4^{\circ} \mathrm{C}$.

Milk fat was determined by creamatocrit with $75 \mathrm{~mm}$ micro-hematocrit tubes following homogenization (26). Briefly, $0.075 \mathrm{~mL}$ of milk was draw into the capillary tubes, sealed, and centrifuged for one minute at $4,750 \mathrm{~g}$ using a hematocrit centrifuge. The height of the cream layer and the milk column were read using a vernier scale with a magnifying glass, and used to calculate the concentration of fat according to Lucas et al. (26).

\section{Data Analysis}

Descriptive statistics were calculated for the concentration of TCE in breast milk and water samples. Samples below the LOD were assigned a value equal to the LOD divided by the square root of 2 (27). Spearman's rank correlation coefficients were computed to determine if correlations exist between breast milk levels of TCE and either drinking, cooking, bathing or laundry water. Classification tree analysis was performed to identify potential subsets of the mothers that may have greater concentration of TCE in their breast milk. Given the small sample size, only the first node of the tree was used for each variable. Fisher's Exact test was used to assess relation of questionnaire responses with detection of TCE in breast milk. Tree analysis was performed using S-PLUS 8.0 (Insightful Corporation, Seattle, WA). All other statistical analysis was performed using STATA IC 11 (StataCorp, College Station, TX). An alpha level of 0.05 was considered significant for all statistical tests.

To facilitate comparison with the US EPA Reference Dose (RfD), ingestion intake was calculated using the mothers' reported daily breastfeeding duration and age-specific breast milk ingestion rates from the US EPA Child-Specific Exposure Factors Handbook (C-S $\mathrm{EFH})(28)$. It was assumed that breast milk flows at $0.12 \mathrm{~g} / \mathrm{sec}$ (29). 


\section{RESULTS}

The LOD was defined as having a signal to noise ratio greater than 3.0 and was equal to 1.0 and $1.5 \mu \mathrm{g} / \mathrm{L}$ for water and breast milk, respectively. TCE was detected in 7 of the 20 breast milk samples (Table 1). Although two mothers provided samples on multiple days, only one had TCE detected in her breast milk on both occasions. The concentrations were 6.0 and 2.0 $\mathrm{ng}$ TCE$/ \mathrm{mL}$. However, these concentrations corresponded to 66.6 and $183.1 \mathrm{ng} \mathrm{TCE} / \mathrm{g}$ fat. The concentration of fat in each sample was 90.4 and $10.6 \mathrm{~g} / \mathrm{L}$, respectively. Although these findings are from only one individual, this may highlight potential temporal variability in the concentration of contaminants and fat in breast milk.

Families used water from multiple sources for their household activities (Table 2). The majority of adults and infants did not consume municipal tap water for drinking nor was tap water used in preparation of their food. Although the results were not significant, mothers who had TCE detected in their breast milk were 4 times as likely to use municipal tap water for cooking compared to mothers who did not have TCE detected in their breast milk ( $\mathrm{p}=$ $0.35)$.

A total of 49 unique water samples were analyzed across the different household uses. TCE was detected in all water samples (Table 3). Concentration of TCE in water was not significantly different by water source or use. The concentration of TCE in water used for bathing and laundry by the infants and the adults was significantly associated with the volumetric and fat adjusted concentration of TCE in breast milk. However, concentration of TCE in water used for drinking and cooking was not associated with the concentration of TCE in breast milk.

No significant associations were identified between detection of TCE in breast milk and infant gender, age, weight or length (Table 4). Mothers of infants with a body mass index (BMI) less than 14 were significantly more likely to have TCE detected in their milk. There were no significant associations between TCE detection in breast milk and infant breastfeeding habits or consumption of other food (Table 5). The majority of the mothers were young ( 25 years of age) and the majority of the households had a low annual income $(<\$ 40,000)$ (Table 6). Mothers who had TCE detected in their milk were more likely to have never lived outside the Ambos Nogales region (Nogales, AZ or Nogales, Sonora), while mothers who did not have TCE detected in their milk were more likely to have lived outside the region. The majority of mothers who had TCE detected in their milk took 5-15 minutes showers, while the majority of mothers that did not have TCE detected in their milk took 16-30 minute showers. However, none of these associations were significant.

The potential ingested intake dose of TCE from breast milk consumption is presented in Table 7. The percentage of infants exceeding the US EPA RfD for TCE is $45 \%$ based upon self-reported breastfeeding frequency and duration. Similarly, 5\% and 20\% of the infants would exceed the RfD based upon the mean and upper breast milk consumption rates provided in the US EPA C-S EFH. Depending upon the milk ingestion rate, the maximum infant intake of TCE was 2-4 times the RfD.

\section{DISCUSSION}

TCE was detected in the breast milk for 7 of 20 (35\%) women residing in Nogales, AZ. All of the women were Latina and half had an infant $<3$ months in age. The majority of households had an annual income $<\$ 40,000$. The level of TCE in breast milk was associated with the concentration of TCE in household bathing and laundry water and was more likely to be detected in the milk of mothers whose infant had a BMI <14. Although perhaps not generalizable to other populations, this exploratory study provides, to the authors' 
knowledge, the first quantified values of TCE in breast milk, filling a key data gap in TCE risk assessment $(3,13)$, and allowing for examination of factors that may be associated with TCE in breast milk.

A previous study that assessed TCE in breast milk, reported that TCE was detected in all breast milk samples analyzed (12). However, no quantified levels of TCE in breast milk or the LOD were provided. It is not clear if the results of the current study are different because of decreased detection frequency due to a higher LOD then the previous study or if fewer women in the current study population were exposed to TCE given that ambient levels of TCE in outdoor air have decreased substantially since the 1980s $(1,30,31)$.

Other studies have reported concentration of other VOCs in breast milk (30, 31). Kim et al. analyzed breast milk samples from Baltimore and North Carolina for chloroform, benzene, toluene and methyl tert-butyl ether, with a LOD of 0.01-0.02 $\mu \mathrm{g} / \mathrm{L}$ (30). Fabietti et al. analyzed breast milk for benzene and toluene in Italy with a LOD of $0.01 \mu \mathrm{g} / \mathrm{kg}$ milk (31). The LOD for both of these studies is substantially lower than the LOD for TCE in the current study. These studies used head-space solid phase microextraction or "purge and trap", while liquid-liquid extraction was used for the current study. Using one of these other methods may lower the LOD for TCE in breast milk in future studies. Given the large variability in milk concentration among VOC compounds in the other studies it is not clear how relevant these concentrations are to the concentration of TCE in the current study. However, the values measured in the current study are within the same order of magnitude of what was determined in previous studies.

Depending upon milk consumption rates, potential TCE intake via this pathway could exceed the US EPA RfD. However, potential TCE intake from breast milk consumption differed substantially when calculated using self-reported consumption versus consumption rates from the US EPA (28). The mother with the highest TCE concentration only reported feeding her infant 2-3 times per day for less than 10 minutes at a time. However, using milk consumption rates from C-S EFH, the estimated dose was 3-5 times higher than that estimated with her self-reported rate. The mother with the highest breastfeeding consumption reported feeding her infant more than 7 times per day for 31-45 minutes per session corresponding to an approximate consumption rate of $2400 \mathrm{~mL} /$ day $(590 \mathrm{~mL} / \mathrm{kg} /$ day) in a 1-2 month old infant. This is 3 times the upper limit in the CS-EFH (28). Better estimates of milk consumption rates in infants are needed to better characterize their risk of exposure from this pathway.

In the current study, a few factors were associated with increased TCE in breast milk and should be further examined to target future interventions. Concentration of TCE in breast milk was significantly correlated with concentration of TCE in water used for bathing and laundry, but not with water used for cooking or drinking. These results suggest that primary exposure to TCE may occur during these activities. Over 10 times more water is typically used in households for bathing and laundry than for cooking or drinking (32). TCE exposure via inhalation from bathing with contaminated water may be 6-80 fold the exposure from ingesting $2 \mathrm{~L}$ of the same water (33). Infants' higher respiratory rates, greater surface area to body-weight ratio, and more permeable skin may make them particularly vulnerable to these exposures (34). More assessments are needed to quantify these exposures and ensure that regulatory limits of TCE in water account adequately for exposures via multiple routes.

The field technician did not report the source of water used for washing breasts. It is likely that the mothers used their typical bathing water. This could be a potential source of sample contamination. However, it is unlikely that residual TCE on the breast would result in a measurable TCE concentration in $100 \mathrm{~mL}$ of breast milk. Residual TCE on the breast from 
washing would also be another significant potential source of exposure to the infant. Depending upon established scope, future studies should consider supplying laboratory grade water for washing the breasts.

TCE is the $3^{\text {rd }}$ most frequently detected contaminant above the MCL (4), and approximately 9-34\% of the drinking water supplies in the US have some TCE contamination (1). Depending upon use, between $68-89 \%$ of the water samples in the current study exceeded the MCL for TCE (Table 3). The analytical method, which is not a US EPA Standard method, was selected from the peer-reviewed literature because of equipment availability. It is not clear if this method may have resulted in higher measured concentrations that should not be compared to the MCL. The significant correlation between TCE concentration in the water and breast milk samples indicates that the relative concentrations in these two matrices are probably correct; however the absolute median value of TCE in the water samples may be higher than reported from other analytical techniques. However, given that the water samples were collected with headspace these reported TCE concentrations in water may represent the lowest probable concentrations. Nevertheless, the strong correlation between TCE content in breast milk and bathing/laundry water, should be considered in developing interventions to reduce exposures to the mother and ultimately the infant.

Mothers who had TCE detected in their milk were 9.6 times more likely to have never lived outside of Nogales. This finding, along with the unusually high rates of SLE and multiple myeloma in this community (20-22), highlights the need for further studies in this region, as well as in other geographic regions for comparison.

TCE is characterized by its ability to accumulate in fat tissues (35). Although levels can decrease quickly following acute exposures, there may be insufficient time for levels to reach baseline following chronic exposures and saturation may be reached over time (36). Breasts have higher concentration of lipophilic solvents than blood or other fatty tissues because of increased blood flow and recirculation of secretions in the duct system, even in non-lactating breasts (37). Typically, the majority of depuration of exogenous substances occurs during the first two months of lactation (38). It has been hypothesized that this might explain lower rates of breast cancer among women with cumulative lactation of at least three months (37). Findings in the current study provide some insight into TCE toxicokinetics that should be better characterized in future studies.

TCE was detected in both samples from only one of the mothers who provided multiple samples. There was a relative percent difference of $102 \%$ and $93 \%$ for the volumetric and fat-adjusted TCE concentrations, respectively. There was also a $158 \%$ relative percent difference in fat composition between the samples. Studies have documented that lipid content of breast milk is highly variable between women, but also in multiple samples from the same woman and is related to duration of feeding, time post-partum, feeding intervals, hind vs. foremilk and left vs. right breast $(38,39)$. The current study supports the notion that variability in fat composition as well as in exposure may contribute to high variability of lipophilic chemical levels in breast milk (38). Future studies should consider collecting multiple samples from each woman.

Other studies have demonstrated that concentration of environmental chemicals in breast milk decreases as the mother's body burden is reduced $(38,40-42)$. Women with an infant with a BMI $<14$ were 5.2 times more likely to have TCE detected in their breast milk. The infant with the lowest BMI was breastfed by the mother with the highest concentration of TCE in her milk who reported the lowest daily breastfeeding duration, suggesting that she may have not depleted her body burden. 
Although not many of the infant, mother or household characteristics were significantly associated with detection of TCE in breast milk, this small exploratory study probably had too little power to assess these risk factors. Additional studies should be performed with greater power to identify important risk factors for detection of TCE in breast milk, that allow for multivariate analyses so that these exposures can be reduced.

To the knowledge of the study authors, this is the first study to report quantified values of TCE in breast milk. Depending upon infant milk consumption patterns, based upon the values reported TCE intake could exceed the US EPA RfD. In this exploratory study there is a significant correlation between the concentration of TCE in breast milk and in bathing and laundry water. These results warrant replication in larger and more in depth studies. Future analyses with a lower LOD should be performed both in Nogales and other communities to obtain a better understanding of the levels of TCE in breast milk and associated risk factors so that intervention strategies can be developed to reduce exposures to nursing mothers and their children.

\section{Acknowledgments}

We wish to thank MCHC for their assistance and support, and the families for their participation. This study was supported by the American Cancer Society (IRG7400128), the Cancer Center Support Grant (CA023074), the Superfund Basic Research Program (P42 ES04940-11) and the Maternal and Child Health Training Grant (HRSA T76MC04925). Analyses in the Arizona Laboratory for Emerging Contaminants were supported by NSF CBET 0722579. Additional funding was provided by the University of Arizona.

\section{REFERENCES}

1. Wu C, Schaum J. Exposure assessment of trichloroethylene. Environ. Health Perspect. 2000; 108(Suppl 2):359-363. [PubMed: 10807565]

2. DHHS (Department of Health and Human Services). [Accessed: February 10, 2012] 2011 CERCLA Priority List of Hazardous Substances. 2012. Available at: http://www.atsdr.cdc.gov/SPL/ index.html.

3. External Review Draft. Washington, DC: United States Environmental Protection Agency; 2001. US EPA Tricholoethylene health risk assessment: Synthesis and characterization. EPA/600/ $P-01 / 022 A$

4. Moran MJ, Zogorski JS, Squillace PJ. Chlorinated solvents in groundwater of the United States. Environ. Sci. Technol. 2007; 41:74-81. [PubMed: 17265929]

5. Gist GL, Burg JAR. Trichloroethylene - a review of the literature from a health effects perspective. Toxicol. Ind. Health. 1995; 11:253-307. [PubMed: 7482570]

6. Cooper GS, Gilbert KM, Greidinger EL, James JA, Pfau JC, Reinlib L, Richardson BC, Rose NR. Recent Advances and Opportunities in Research on Lupus: Environmental Influences and Mechanisms of Disease. Environ. Health Perspect. 2008; 116:695. [PubMed: 18560522]

7. Wartenberg D, Reyner D, Scott CS. Trichloroethylene and cancer: epidemiologic evidence. Environ. Health Perspect. 2000; 108(Suppl 2):161-176. [PubMed: 10807550]

8. Scott CS, Chiu WA. Trichloroethylene Cancer Epidemiology: A Consideration of Select Issues. Environ. Health Perspect. 2006; 114:1471-1478. [PubMed: 16966107]

9. Anderson L, Diwan B, Fear N, Roman E. Critical windows of exposure for children's health: cancer in human epidemiological studies and neoplasms in experimental animal models. Environ. Health Perspect. 2000; 108:573-594. [PubMed: 10852857]

10. US EPA Supplemental Guidance for Assessing Susceptibility from Early-Life Exposure to Carcinogens. Washington, DC: United States Environmental Protection Agency; 2005. EPA/630/ $R-03 / 003 F$

11. Fisher J, Mahle D, Bankston L, Greene R, Gearhart J. Lactational Transfer of Volatile Chemicals in Breast Milk. Am Ind Hyg Assoc J. 1997; 58:425-431. [PubMed: 9183837] 
12. Pellizzari ED, Hartwell TD, Harris BS 3rd, Waddell RD, Whitaker DA, Erickson MD. Purgeable organic compounds in mother's milk. Bull. Environ. Contam. Toxicol. 1982; 28:322-328. [PubMed: 7082873]

13. Pastino GM, Yap WY, Carroquino M. Human variability and susceptibility to trichloroethylene. Environ. Health Perspect. 2000; 108(Suppl 2):201-214. [PubMed: 10807552]

14. Froehling J. ... and not a drop to drink. Nogales International. 2007 Jun 22.

15. ADEQ Wellhead Protection Guidance. Tucson, AZ: Arizona Department of Environmental Quality; 1997.

16. Bowen MM, Kontuly T, Hepner GF. Estimating maquiladora hazardous waste generation on the US/Mexico border. Environ. Manage. 1995; 19:281-296.

17. Velazquez L, Munguia N, de los Angeles Navarrete M, Zavala A. An overview of sustainability practices at the maquiladora industry in Mexico. Management of Environmental Quality. 2006; 17:478-489.

18. Sanchez RA. Health and Environmental Risks of the Maquiladora in Mexicali. Nat. Resour. J. 1990; 30:163.

19. ADHS (Arizona Department of Health Services). [Accessed: September 30, 2008] Arizona Cancer Registry. 2008. Available at: heatlthdata.az.gov.query.modeul_selection/azcr/AzCRSelection.html.

20. Clay R. Still moving toward environmental justice. Environ. Health Perspect. 1999; 107:A308_ A310. [PubMed: 10339458]

21. Balluz L, Philen R, Ortega L, Rosales C, Brock J, Barr D, Kieszak S. Investigation of Systemic Lupus Erythematosus in Nogales, Arizona. Am. J. Epidemiol. 2001; 154:1029-1036. [PubMed: 11724719]

22. Walsh BT, Pope C, Reid M, Gall EP, Yocum DE, Clark LC. SLE in a United States-Mexico Border Community. JCR: Journal of Clinical Rheumatology. 2001; 7:3-9.

23. Belson M, Kingsley B, Holmes A. Risk Factors for Acute Leukemia in Children: A Review. Environ. Health Perspect. 2007; 115:138-145. [PubMed: 17366834]

24. Needham LL, Ryan JJ, Fürst P. GUIDELINES FOR ANALYSIS OF HUMAN MILK FOR ENVIRONMENTAL CHEMICALS. Journal of Toxicology and Environmental Health, Part A. 2002; 65:1893-1908. [PubMed: 12470493]

25. Brown SD, Dixon AM, Bruckner JV, Bartlett MG. A validated GC-MS assay for the quantitation of trichloroethylene (TCE) from drinking water. International Journal of Environmental and Analytical Chemistry. 2003; 83:427-432.

26. Lucas A, Gibbs JA, Lyster RL, Baum JD. Creamatocrit: simple clinical technique for estimating fat concentration and energy value of human milk. Br. Med. J. 1978; 1:1018-1020. [PubMed: 638579]

27. Hornung RW, Reed LD. Estimation of average concentration in the presence of nondetectable values. Appl. Occup. Environ. Hyg. 1990; 5:46-51.

28. Washington, DC: United States Environmental Protection Agency; 2008. US EPA Child-Specific Exposure Factors Handbook (Final Report). EPA/600/R-06/096F

29. Prime DK, Geddes DT, Spatz DL, Robert M, Trengove NJ, Hartmann PE. Using milk flow rate to investigate milk ejection in the left and right breasts during simultaneous breast expression in women. International Breastfeeding Journal. 2009; 4:10. [PubMed: 19852864]

30. Kim SR, Rolf U, Buckley TJ. Volatile organic compounds in human milk: methods and measurements. Environ. Sci. Technol. 2007; 41:1662-1667. [PubMed: 17396657]

31. Fabietti F, Ambruzzi A, Delise M, Sprechini MR. Monitoring of the benzene and toluene contents in human milk. Environ. Int. 2004; 30:397-401. [PubMed: 14987872]

32. Andelman JB. Human exposures to volatile halogenated organic chemicals in indoor and outdoor air. Environ. Health Perspect. 1985; 62:313-318. [PubMed: 4085436]

33. Andelman JB. Inhalation exposure in the home to volatile organic contaminants of drinking water. Sci. Total Environ. 1985; 47:443-460. [PubMed: 4089611]

34. Hubal EAC, Sheldon LS, Burke JM, McCurdy TR, Barry MR, Rigas ML, V Z, Freeman NCG. Children's exposure assessment: A review of factors influencing children's exposure, and the data available to characterize and assess that exposure. Environ Health Perspect. 2000; 108:475-486. 
35. Albanese RA, Banks H, Evans MV, Potter LK. Physiologically based pharmacokinetic models for the transport of trichloroethylene in adipose tissue. Bull. Math. Biol. 2002; 64:97-131. [PubMed: 11868339]

36. Perbellini L, Mozzo P, Brugnone F, Zedde A. Physiologicomathematical model for studying human exposure to organic solvents: kinetics of blood/tissue n-hexane concentrations and of 2, 5hexanedione in urine. Br. J. Ind. Med. 1986; 43:760-768. [PubMed: 3790456]

37. Labreche FP, Goldberg MS. Exposure to organic solvents and breast cancer in women: a hypothesis. Am. J. Ind. Med. 1997; 32:1-14. [PubMed: 9131206]

38. LaKind JS, Amina Wilkins A, Berlin CM Jr. Environmental chemicals in human milk: a review of levels, infant exposures and health, and guidance for future research. Toxicol. Appl. Pharmacol. 2004; 198:184-208. [PubMed: 15236953]

39. Spencer SA, Hull D. Fat content of expressed breast milk: a case for quality control. Br. Med. J. (Clin. Res. Ed). 1981; 282:99-100.

40. LaKind JS, Berlin CM, Naiman DQ. Infant exposure to chemicals in breast milk in the United States: what we need to learn from a breast milk monitoring program. Environ. Health Perspect. 2001; 109:75-88. [PubMed: 11171529]

41. Hobson WL, Knochel ML, Byington CL, Young PC, Hoff CJ, Buchi KF. Bottled, filtered, and tap water use in Latino and non-Latino children. Archives of Pediatrics and Adolescent Medicine. 2007; 161:457. [PubMed: 17485621]

42. Anadu EC, Harding AK. Risk perception and bottled water use. Journal American Water Works Association. 2000; 92:82-92. 


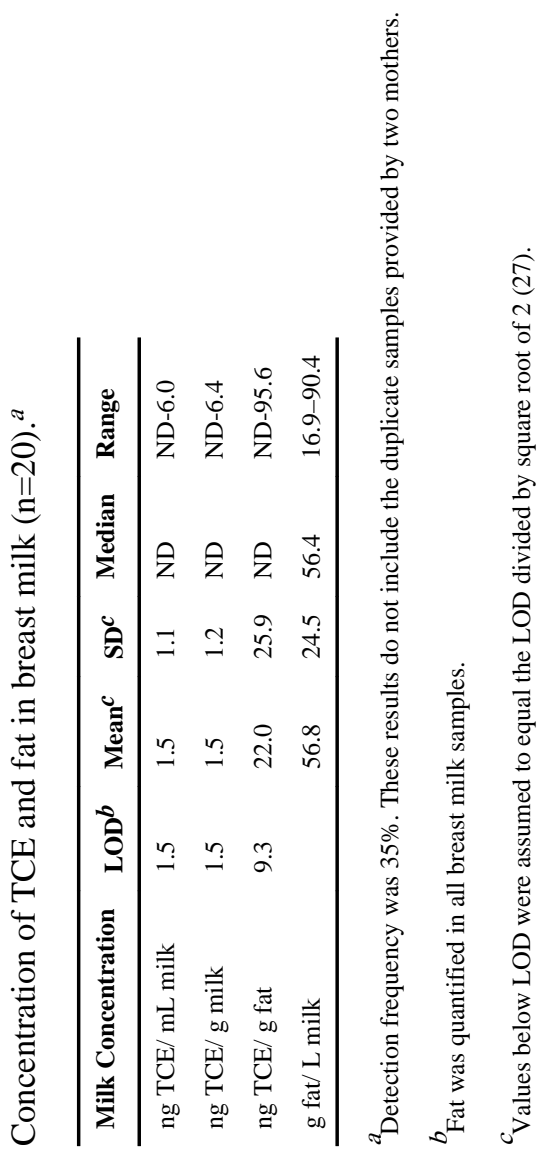

Environ Sci Technol. Author manuscript; available in PMC 2013 July 02. 


\section{Table 2}

Primary source of water used for various household activities by adults and infants ( $\mathrm{n}=20$ households).

\begin{tabular}{|c|c|c|c|c|}
\hline Use & Municipal Tap & Bottled & Well & Vending $a$ \\
\hline \multicolumn{5}{|l|}{ Adult } \\
\hline Drink & $2(10 \%)$ & $8(40 \%)$ & $1(5 \%)$ & $9(45 \%)$ \\
\hline Cook & $9(40 \%)^{b}$ & $4(20 \%)$ & $1(5 \%)$ & $6(30 \%)$ \\
\hline Bathing & $19(95 \%)$ & 0 & $1(5 \%)$ & 0 \\
\hline Laundry $c$ & $17(85 \%)$ & 0 & $1(5 \%)$ & 0 \\
\hline \multicolumn{5}{|l|}{ Infant $^{d}$} \\
\hline Drink & $1(5 \%)$ & $11(55 \%)$ & 0 & $6(25 \%)$ \\
\hline Cook & $8(40 \%)$ & $3(15 \%)$ & $1(5 \%)$ & $5(25 \%)$ \\
\hline Bathing & $19(95 \%)$ & & $1(5 \%)$ & \\
\hline Laundry $c$ & $17(85 \%)$ & 0 & $1(5 \%)$ & 0 \\
\hline
\end{tabular}

${ }^{a}$ Vending includes water purchased from vending machines in front of grocery stores or from stores specializing in selling water. Typically individuals supply their own containers.

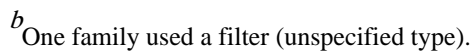

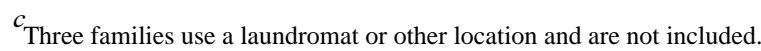

$d$ Two infants exclusively consumed breast milk at time of collection and are not included. 


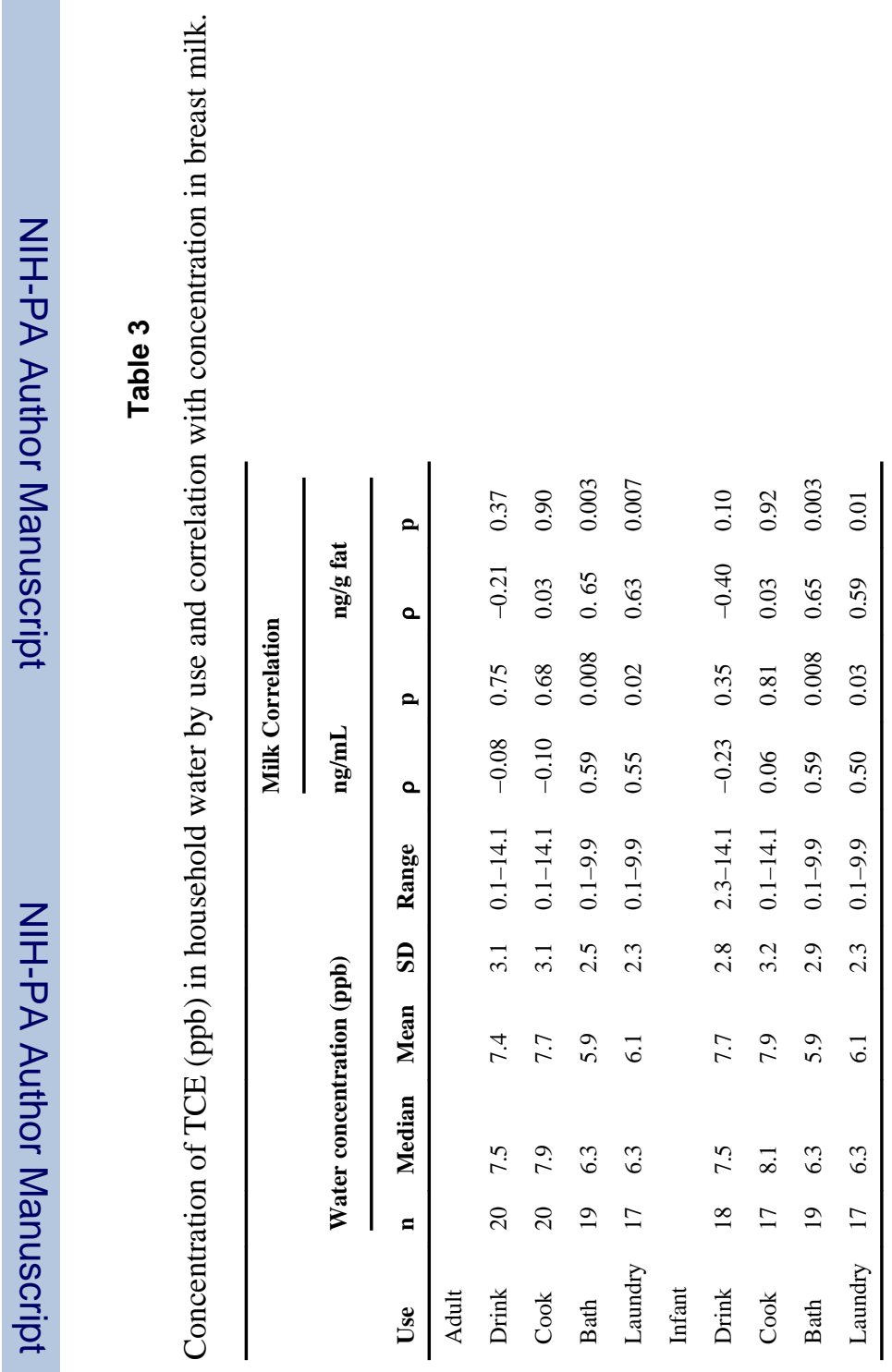




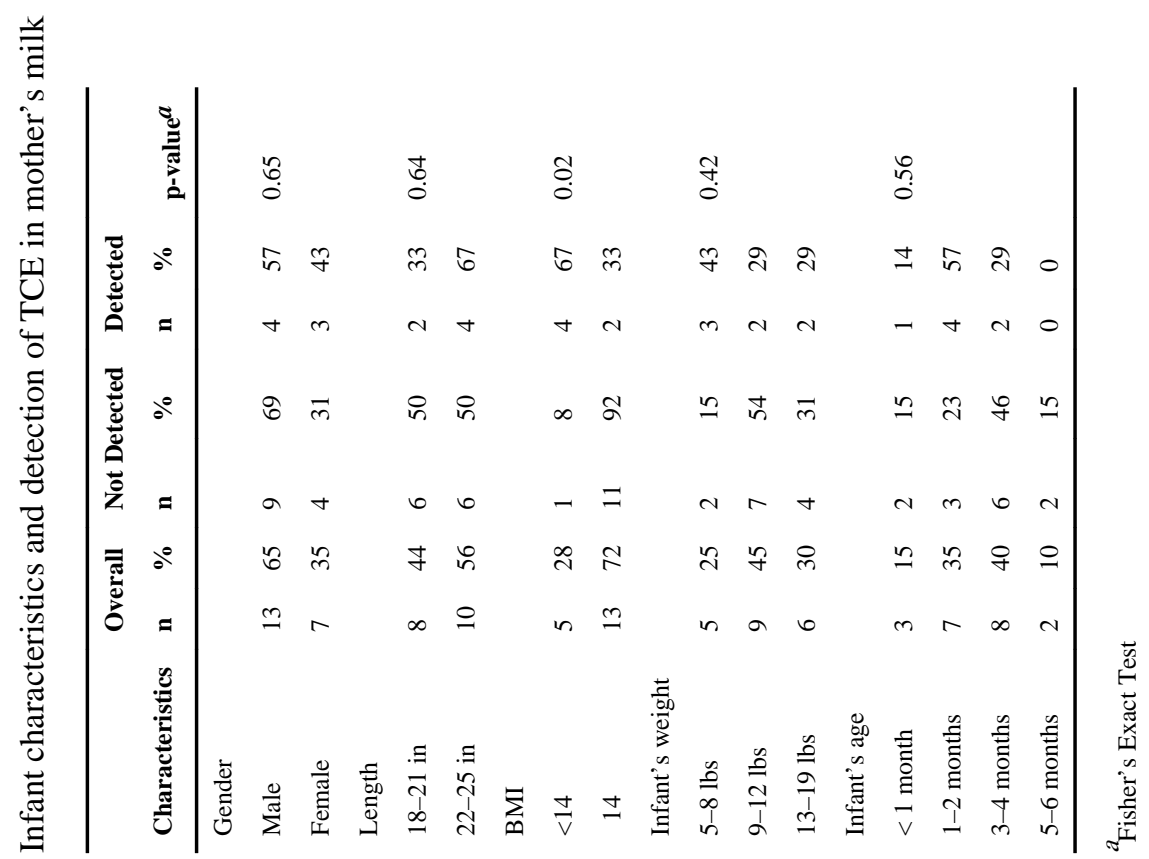




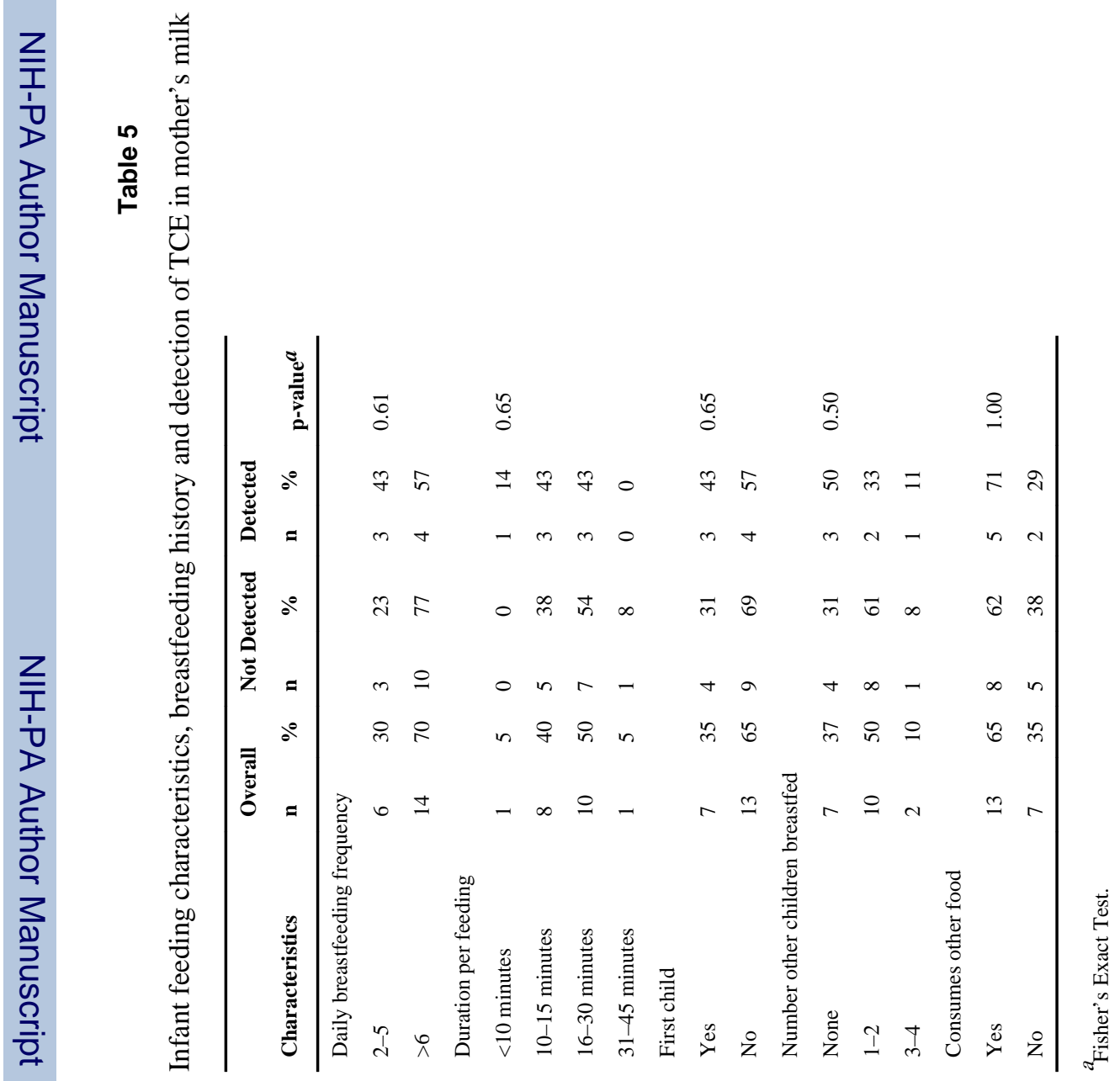




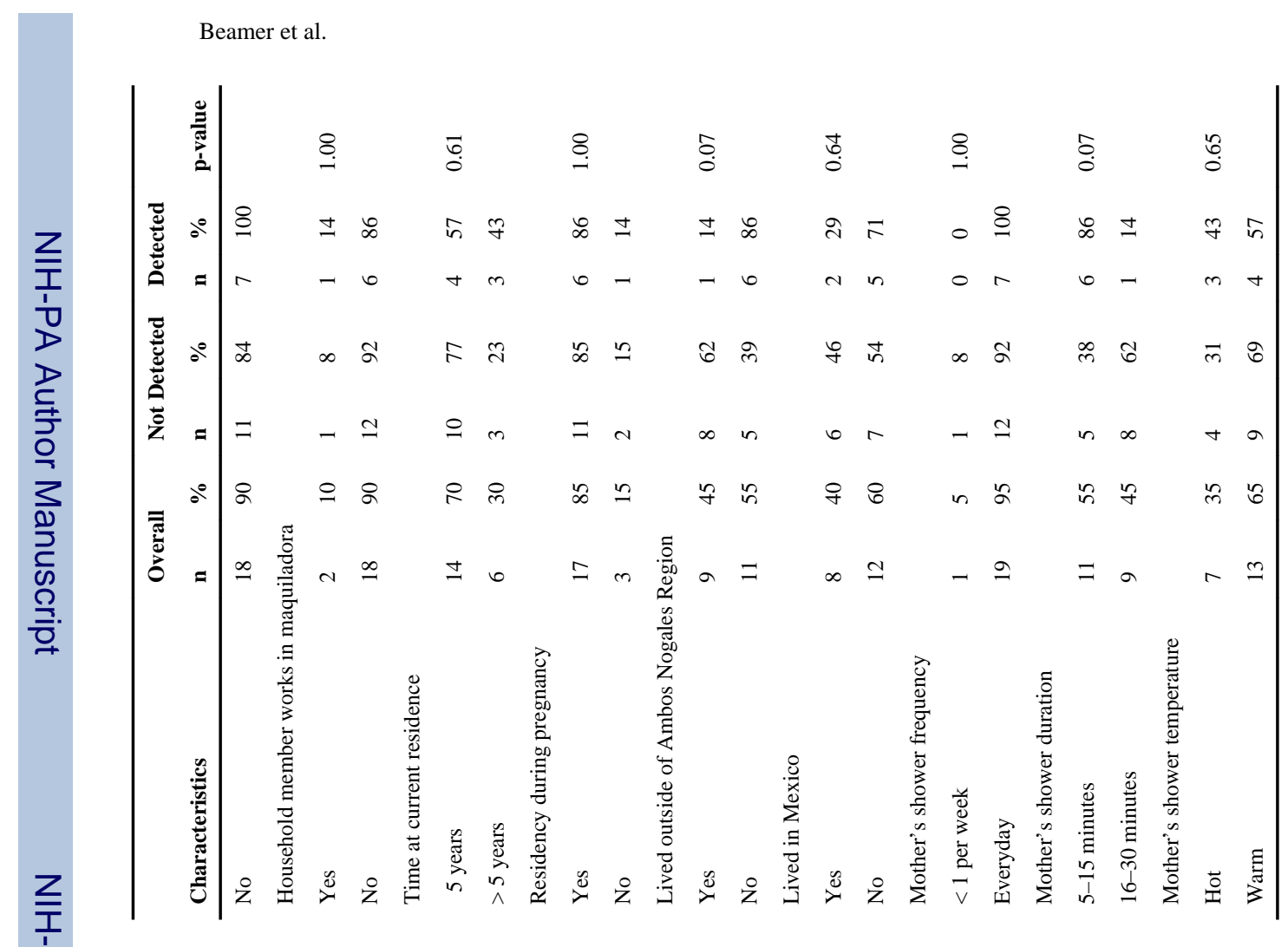


Table 7

Potential intake (mg/kg/day) of TCE from breast milk. US EPA RfD is $3.0 \times 10^{-4} \mathrm{mg} / \mathrm{kg} / \mathrm{day}$.

\begin{tabular}{lllll}
\hline & Median & Mean & SD & Range \\
\hline Self-reported consumption & $2.3 \times 10^{-4}$ & $2.3 \times 10^{-4}$ & $1.7 \times 10^{-4}$ & $4.0 \times 10^{-5}-6.4 \times 10^{-4}$ \\
C-S EFH mean consumption & $1.1 \times 10^{-4}$ & $1.7 \times 10^{-4}$ & $1.6 \times 10^{-4}$ & $8.0 \times 10^{-5}-8.4 \times 10^{-4}$ \\
C-S EFH upper percentile & $1.4 \times 10^{-4}$ & $2.3 \times 10^{-4}$ & $2.2 \times 10^{-4}$ & $1.1 \times 10^{-4}-1.1 \times 10^{-3}$ \\
\hline
\end{tabular}

